\title{
Contemporary problems and solutions for early childhood music education in Zambia
}

\author{
Mulenga Emmanuel.T a, ${ }^{\mathrm{a},{ }^{*},}$, $\operatorname{Tan} \mathrm{Tu}^{\mathrm{a}, 2}$, Dixian Teng a,3 \\ a Department of Music Education, Nanjing University of the Arts, Nanjing, 210013 China \\ ${ }^{1}$ tinnashmulenga16@yahoo.com*; ${ }^{2} 1625900568 @$ qq.com; ${ }^{3} 1269842048 @$ qq.com \\ * corresponding author
}

ARTICLE INFO

Article history

Received 2021-05-12

Revised 2021-05-29

Accepted 2021-06-19

Keywords

Zambia

Early childhood education

Children's music curriculum

Problems and solutions

\section{ABSTRACT}

Music education is now receiving attention from all works of life especially from psychologist studying children's mental development scientist has revealed that music education in early childhood helps children develop auditory sense nerves and most of the musical activities aid cycle motor development and children who learn musical instruments have a strong memory function abilities which help them to solve problems in other learning subjects. Therefore, learning music in early childhood educations is the bed lock of future education. This is the main reason why early childhood music education researchers are working day and night year in year out to find proper teaching methods to use when interacting with children. As much focus is devoted to studies on children's music education aiding cognitive learning in developing countries, it is a wake-up call for Zambia to develop music education in early childhood education. So this paper investigation endeavors to point out problems and offers sound solutions on the most proficient method to improve music schooling in early childhood education in Zambia by performing a complete overview of the evidence on elementary school education curricula in both government-funded and non-government schools.

This is an open-access article under the CC-BY-SA license.

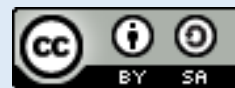

\section{Introduction}

Globally, Early Childhood Education is considered the most fragile period in any education system. This is because every academic achievement of children in the future depends on early childhood education. This is why early childhood education programs are designed to build cognitive and motor development, supporting learning other subjects. "Play facilitates holistic development and provides opportunities for children to learn not only the social and cultural values but also the skills and competencies necessary for survival and become productive members of their communities [1]. The curriculum educational reforms are meant to improve the music education system and ensure children's cognitive development is fulfilled. However, the current Zambian educational curriculum gives music educators many questions about the future of early childhood music education. It is now a big concern because the education policies on curriculum implementation have shown little interest in music for early childhood education. "The Ministry of Education acknowledges the vital role of early childhood education in the multi-dimensional development of young children [2].

However, the current situation on both music literacy and music performances in Zambian public schools is evidence enough to show that music education truly needs attention from the grass-roots level [3], which Is the foundation of music education for a progressive country; the most worrying fact is that early childhood music education is sidelined by most government schools left to be operated and regulated by the privet schools whose curriculum varies from school to school. 
There is too little even to admire or respect the current music education in government-funded schools in Zambia on every level of education [4]. Early childhood music education in public schools is confronting many challenges with regards to the implementation of music education on the grounds that there are no particular music programs that blend with the general curriculum at the early childhood education level, and this has badly affected children's performances in other subjects like mathematics, science, and other many others. On the other hand, children's poor performance in the general education system in public schools is caused by a lack of musical skills and enough knowledge on the ideal teaching methods in music education coming from teachers and also lack of music materials to help in building a solid foundation of music education in early childhood. One can easily conclude that music education in early childhood still has no proper distinctive educational objectives after looking at the evidence presented by this research and other research investigations done in the past concerning the quality of music education in Zambian schools. In 2016 Bibian Kalinde, in her study, also gave a clear picture of the problems early childhood music education is facing in Zambia; she further said that lack of government official policy pronouncements on early childhood music curriculum had made music in early childhood suffer setbacks [5]. In 2009 Aloysio K Mumpuka, in his study, lamented on the inferior status of music education at lower levels in Zambia; he revealed that one of the problems of music education in Zambian public schools was the lack of suitable music policies on the curriculum [6].

Mary Mwila lamented over the poor state of music education in public schools at all education levels in Zambia; she further explained the importance of music education in children's growth. Many professionals in early childhood education in Zambia have also recognized the need for music in children's education. However, the problem has remained the same in government-funded schools; music as a subject does not receive enough time to implement whenever it appears on the school timetable [7], [8]. She believed there is much to be done, especially on the curriculum and music teacher training. The conducted studies on music education by music educators and other early childhood education providers in Zambia suggest strengthening music education in public schools by offering practical solutions to the long-overdue poor situation. The author firmly believes that adopting or introducing the suggested suitable music curriculum for children in this study will also help music educators in elementary schools improve their teaching methods. The music curriculum will guide them on handling specific topics, which will stop teachers from random music teaching.

After performing a complete overview of the evidence on elementary schools education curricula in both government-funded and non-government schools in Lusaka and the accumulated data of developed countries is worth contributing positively to the construction or development and reformation of the elementary school's music curricula in Zambia since its disclosing significant holes in the current early childhood education programs of the Zambian schooling framework and other African countries. Another interesting Significance is how this research investigation perceives the importance of a sound music education curriculum in elementary school education from already developed countries broadens the imitations of the global standards of early childhood music education. Also, it aims to advance the use of music activities to diverse subjects of elementary school teaching. The recommended systematic music education program or curriculum from this research investigation will undoubtedly help improve music schooling by giving answers or precise responses to the long-late early childhood music education issues in both government-funded and private elementary schools in Zambia.

The enormous information and disclosure of this research examination on the advantages of musical exercises in early childhood education will impact the public authority under the education sector and all education policymakers to rapidly embrace a good music education plan or curriculum suitable for early childhood. This research investigation is one of the positive contributions or commitments towards safeguarding and advancing quality music training on instructing and learning in early childhood of public and non-public schools in Zambia. The new data might prompt the disclosure of native teaching techniques for music to advance or promote Zambian culture and musical legacy. This investigation can develop educators' certainty or confidence and make a prolific way for music appreciation among music teachers handling early childhood education. Then again, it will give positive knowledge and insight to early childhood education mentors in various universities to support early childhood student teachers by encouraging them to enhance their training on music abilities as they train to be viable instructors in early childhood education. This research investigation will add to the current investigations of children's music education in Zambia from a more extensive viewpoint. 


\section{Method}

This research endeavors to design the most proficient method to improve music schooling and its usage in early childhood education in Zambia. This investigation utilized various examination techniques: observation methods, comparison methods, and literature review strategies. The vast majority of the gathered information on early childhood music education or instruction in Zambia and other nations in this research was gathered utilizing various mediums, libraries, online data recoveries, and video and phone interviews. Early childhood music education programs or curriculum data from various developed nations gave indisputable proof and backings to consider in the development or construction of music education curricula for public and government-funded early childhood in Zambia. Furthermore, the summed up instructive arrangements and educational policies on music education programs or early childhood curriculum execution in early childhood from the abroad nations helped this investigation to build up the instructive idea and distinctive strategies on music teaching techniques and also build valuable strategies assessment ability of kids music training, the information further helped in exposing the importance of music teacher education and the use of significant music materials. Direct Observations were additionally made on how music is led in early childhood in China, for the analyst has been studying music education in China for four great years.

On the other hand, observation methods were applied to other countries using internet resources of music educational videos. The same recorded recordings on YouTube by celebrated early childhood music teachers helped collect an appropriate early childhood music education program or curriculum. These renowned teachers focused on the significance of actualizing music training in early childhood to accomplish the solid cognitive development of children through music activities and game-related exercises. Table 1 shows that music education shares little time with other arts-related subjects in the current early childhood curriculum, for it is under expressive arts.

Table 1. Time Allocation at Early childhood Education [9]

\begin{tabular}{cc}
\hline Learning Areas & Time Allocation per Week \\
\hline Social Studies & 2 hours \\
Pre-Literacy and Language & $3^{1 / 2}$ hours \\
Pre-Mathematics & $31 \frac{1}{2}$ hours \\
Environmental Science & $3 \frac{1}{2}$ hours \\
Expressive Arts & $2 \frac{1}{2}$ hours \\
Total & 15 hours \\
\hline
\end{tabular}

\section{Results and Discussion}

Early childhood Music education in Zambian has continued to be a big concern to the ministry of education and the general public. "At present, only a tiny minority of Zambia's children can profit from education at this level. This is because there are relatively few pre-schools. The majority of these are privately owned and operated, though local councils run some. All aim to meet their costs through fees, which few average Zambian households can afford. In addition, most pre-schools are found in urban areas where the population is large enough to ensure their viability. Although some rural preschools exist, they are few and far between. Because of the associated costs, immensely few poor children enjoy education benefits at this level; it reaches very few rural children [10]. Therefore, early childhood music educators in Zambia have been fighting to implement quality music education in early childhood schools.

The advocated curriculum should combine the traditional teachings of music education and embrace international instructional teaching methods."The curriculum at this level has been standardized and linked to Grade 1. Previously, centers used different curricula; therefore, some learning activities did not provide a smooth transition to Grade 1 . To avoid this, there will be a need to develop a national curriculum for ECE for use by all the providers in Zambia and create learning areas linked to Primary School [11]. Music education in this early childhood curriculum is needed to bring out children's social character and cultivate a patriotic mind towards culture through music activities. It is also used to evaluate children's emotions as they learn other educational subjects. However, the Zambian education system's early childhood music curriculum gap is a considerable concern, even though one is fully aware that teaching other subject areas requires incorporating musical activities to understand language and math topics fully. For example, in Lusaka, early 
childhood centers that attempt to offer music education find it difficult because there is no specific music curriculum to fit early childhood music education [12].

\subsection{Problems faced in early childhood music education in Zambia}

The first major problem in early childhood education in Zambia is the lack of a standard music curriculum specific for early childhood that can compete and qualify on the international standard for children's music education. As a result, the curriculum for early childhood will be dominated by play and pre-learning activities based on the following learning areas: Social Studies, Integrated Science, Pre - Mathematics, Literacy and Language, Expressive Arts [11]. At present, there is too little even to admire the current music education in government-funded schools in Zambia on every level of education. Early childhood music education in public pre-schools is confronting many challenges with regards to the implementation of music education on the grounds that there are fewer or no educational facilities to support music programs that can blend with the general curriculum at the early childhood education level, and this has badly affected children's performances in other subjects like mathematics, science, and other many others. On the other hand, children's poor performance in the general education system in public schools is caused by a lack of musical skills and enough knowledge on the ideal teaching methods in music education coming from teachers and also lack of music materials to help in building a solid foundation of music education in early childhood. Therefore, there must be a careful plan, research, selection, and adapt the material at the beginner teacher stage. To do this, teachers must be familiar with the national curriculum for music. For example, during an inspection, there will be times when the teacher will be held accountable for the work done in class on this legal document [13], [14]. Now in the case of government elementary schools, One can easily conclude that music education in early childhood still has no proper distinctive educational objectives after looking at the evidence presented by this research and other research investigations done in the past concerning the quality of music education in Zambian schools.

Lack of government and community cooperation to carry out high-quality music education for children has deprived the practical purpose of music education on socialization and creativity development on children's growth. Because of this, children have not fully explored the connecting factors of music and the environment surrounding them. The idea of artists working in the community sprang from creating arts centers in the late 1960s, where participatory workshops allowed for sharing ideas and encouraged a much more equal partnership between artists and clients. For music, this might have taken the form of a production, where the workshop leader encouraged experimentation and improvisation and facilitated new skills to create a performance piece [15]. Now Music in Early childhood education in government-funded schools in Zambian is almost absent because the community has not received enough knowledge benefits of music education in developing children's multiple intelligence or cognitive development. In American Public elementary schools were asked whether they had partnerships or collaborations with various artists or other entities to help meet the school's arts education goals in 2008-09. Forty-two percent of schools indicated that they had partnerships with cultural or community organizations. The percentage of schools that reported other types of partnerships or collaborations ranged from 31 percent for individual artists and craftspeople to 7 percent for the community school of the arts [16].

Lack of government's strategic assessment of children's music curriculum and poor early childhood teacher preparation has badly affected children's music education in Zambia. Practical evaluation, whether of individual students, groups of students, teachers, or programs, can be accomplished with greater ease if it is based on an articulated curriculum and substantive data [17]. A successful early childhood music education system should always include acquiring new evaluation information on early childhood music education by assessing the competence of elementary school music teachers that can assess kids without killing the desire for music education in them. Moreover, some pedagogical benefits of music in the mother tongue are those applicable to music in general education [18]. Psychologists have discovered that dealing with young children's education requires calculated educational motives to entice their behavior towards the goals of the curriculum. The current problems faced in early childhood education music evaluation result from a lack of professional music teachers to handle music education in children. Untrained teachers teaching music in early childhood education fail to choose appropriate learning resources and appropriate evaluation methods necessary to build a strong music foundation for children [19]. 


\subsection{Recommendations and solutions to solve the problems faced in early childhood music education in Zambia}

The government should formulate a policy on compulsory music education for young children. To provide quality music education in the education system, the country should have a deliberate policy that focuses on improving the music education foundation in early childhood education [20]. Learning from already well-established early childhood music education systems of developed countries, a specific music curriculum for children is one paramount material that is structured to bring out the musicality of children, and not only does it promote cognitive development, but it also stimulates the ability of children learning other subjects with minor problems faced. So it is only proper that the Zambian government emulate the progress recorded from early childhood music education in developed countries. In developed nations, state systems for early childhood education (ECE) are designed to increase the effectiveness of early childhood services by linking young children and their families to the support they need. State systems for ECE programs coordinate and regulate the various services for children from birth to age five and their families. The music education system from developed countries like America, China, and European countries like the United Kingdom and Greece has proven or demonstrated its effectiveness by supporting music education in early childhood education settings. For example, in America, the education system for early childhood education starts from child care, preschool, and kindergarten. These early childhood education settings are designed to develop children's cognitive abilities and equip kids with the basic information needed for future education. Every early childhood education setting in America has its specific music curriculum that is appropriate in meeting up the educational objectives of children according to their age.

There is a big difference between Lusaka private preschools and government schools regarding their educational facilities; private schools have invested vast amounts of money in designing the school with additional facilities that support music education and extra-curricular activities. Zambia needs to increase resources to fund activities that have an immediate impact on learning. Moreover, the recently launched revised national curriculum will require significant resources to support its implementation [9]. At the same time, most government schools have poor infrastructures that are not good enough for learning music activities in normal circumstances. Private preschools in Lusaka have modern libraries stocked with new editions of books, and they have advanced learning specialized materials like computers which help children in learning and research. However, government schools have libraries with old editions of books, and the same books are not even enough to meet the demand. Improving music facilities will help promote music education; more appropriate music teaching materials should be provided in schools to help early childhood music teachers implement music because the lack of materials is not solely an issue for students [21].

Different musical instruments should be provided to children to build the children's interest in music activities. Instruments like piano, guitar, traditional drums, and xylophones are to be provided in every classroom because these instruments can enhance children's music understanding by producing familiar music sounds that trigger exciting emotions in children's learning abilities as they interact with their environment. Moreover, as the world is advancing in technology, there is a need for the Zambian government to invest in digital music facilities that will allow the use of cartoons and other modern music materials that promote game activities in children's education. There are currently few books written on early childhood education in Zambia. The need for such resources is justified because $68 \%$ of Zambian children are not accessing pre-primary education relative to primary education in this country [22]. Under the education sector, the Zambian government needs to consider integrating new and exciting music education programs in the early childhood education curriculum framework and ensure that this childhood music education program includes everybody in the general public to commemorate a sound change in the music instruction of children. Educational program usage is an aggregate work, where collaboration is required, mainly when dealing with children's educational growth. Everybody ought to be associated with arranging and designing curriculum implementation and evaluation technics [23].

Since the inception of music education in elementary schools, individuals have consistently met up to frame rules on the best way to give valuable data for the progression of human information. The senior community citizen expects kids to acquire data that causes them to recognize themselves with specific traditional standards and culture. A straightforward method of passing on data in kids is through music schooling; it has been demonstrated by the two philosophers and psychologists that to have fruitful education for young children, an administration cannot sideline the vital job of local area 
individuals with regards to giving direction and criticism during the assessment on the adequacy of educational plan usage. Unfortunately, music in Early childhood education in government-funded schools in Zambian is almost absent because the community has not received enough knowledge on the benefits of music education in developing children's multiple intelligence or cognitive development. Parents in Zambia seemed to acknowledge the benefits of play-based learning to children, but most parents supported a more academic-oriented path; hence, parents were more inclined to support teacher-directed activities focused on acquiring academic knowledge at ECE Centers [24].

The lack of knowledge on the importance of music education by the communities cripples the education system because music education does not deserve society's deserved support. The music subject in the curriculum is taken to be a useless time-consuming subject. Therefore, the ministry of education needs to carry along the communities for early childhood music curriculum implementation; this is one of the secrets for high-quality early childhood music education in developed countries. Music deserves a rightful place at the core of a preschool through the elementary school curriculum. All children have equal rights to knowledge of their cultural heritage, including music, to develop their aural, artistic, expressive, and musical sensibilities [25]. Moreover, allowing society to collaborate with early childhood music providers does not only increase the chances of improving the quality of early childhood music education in Zambia. However, it will also help in removing the resistance music education has been receiving from the community.

Zambian Parents need to understand that they also have the responsibility of evaluating their children's education by ensuring that subjects that promote children's cognitive and motor skills are included in the curriculum. The ministry of education needs to create awareness of the importance of music education in children's development to the general public. Early childhood music education should develop and reach its great potentials in Zambia. It is essential to see that the same focus and attention given to early childhood music education by different developed countries in teacher training institutions provide a high quality of musical training in both skills and theories connected to their curriculum. The same focus and determination should be embraced to develop early childhood music education in public schools in Zambia. The Ministry of education should intentionally initiate workshops for in-service teachers in order for them to upgrade their teaching methodologies. It is also vital for the Zambian music education system to work with different music education systems of other developed nations, which will help develop meaningful educational policies towards the growth of the early childhood music curriculum. It is heartbreaking to see that many early childhood educators have little preparation or experience implementing music education in their classrooms, killing children's creative potentials. Studies have revealed that child play was not considered a significant aspect of ECE teaching and learning. Child Play was considered an activity that the children were made to engage in after formal learning came to an end [26].

If music education improves in Zambia, the flexibility of service delivery during and after teacher training should promote a favorable learning environment that stimulates children's musical abilities. Excellence in early childhood education (ECE) programs are built on a workforce that promotes continuous program improvement. Professional development is a cornerstone of this process [27]. Every music educator should be a source of inspiration for creative thinking in children, Because Children's artistic creativeness is built on the existing musical experiences from teachers. Hence, building multiple intellectual abilities through music activities is a process that requires a deliberate move from the music educators by encouraging children's music ideas through the acknowledgment of every little effort children makes musically. "In the current educational climate, teachers are required to negotiate a balance between mandated academic learning and developmentally appropriate play-based pedagogical practices [28]. This can only be archived mainly when the teacher handling early childhood education is equipped with the required skills in children evaluation and curriculum implementation. In developed nations. In nursery schools, the class teacher is fully responsible for teaching music, which is part of aesthetic education, including music, art, and drama. In the vast majority of early childhood education, music is taught by music specialists. Moreover, on the other hand, the world keeps on improvising in technology; there is an agent need for early childhood music teachers in Zambia to be updated with new technology facilities for early childhood education that will help them to simplify music concepts and help to make lessons more interesting during classroom time. 
All over the globe, Evaluation of music in early childhood challenges the education implementers on improving the quality of policies they make towards children's education. This is because operating early childhood music education programs is not easy; it requires proper educational strategies to qualify appropriate teaching material and curriculum implementation methods. Through the early childhood music curriculum, the government under the ministry of education should be conscious of providing guidelines for evaluating the teaching materials and music experiences in the general education system. Music implementers need to make sure that desired habits and the proper techniques are developed in early childhood. If this is not handled in the early stages of a child's education, it becomes a significant challenge to control bad music techniques learned from childhood. So the need to acquire knowledge on music evaluation in Lusaka public early childhood will allow the ministry of education to check the effectiveness of the curriculum through critical analysis on both learning and teaching objectives of music education in early childhood education. Evaluation in developed countries has given them a chance to capitalize on the resources to explore children's intelligence in music education. A successful early childhood music education system should always include acquiring new evaluation information on early childhood music education by assessing the competence of early childhood music teachers who can assess kids without killing their desire for music education.

Considering the knowledge acquired about early childhood music education in china, appropriate learning resources and evaluation are necessary to build a strong music foundation. Supporting children's development is a crucial endeavor in early childhood education and care [29]. It is also important to realize that cultural musical activities also have a significant influence on education, there is a need to include cultural materials in the children's music curriculum in order to obtain the desired goals, and it becomes easy to evaluate music from the cultural perspective because children are already familiar with their music tradition. Even in African history, elders evaluated learning using cultural musical practices that were interactive, and the materials helped children build a culture of working together. So whenever the elders saw that children could cooperate and perform music together, their evaluation objectives were achieved.

\section{Conclusion}

There is a need to strengthen music education in public schools by offering practical solutions to long-overdue poor early childhood education in Zambia. Over the years, music researchers in Zambia have identified that quality music education in early childhood schools is not an integral part of children's education. This is mainly because there is no proper music curriculum for early childhood in public schools, and the admission criteria for teacher training programs are of low professional standards. The government policy on teacher education should be consistently revised and ensure that early childhood and other education level teacher education courses are restricted and subjected to a preliminary selection process, including interviews for candidates to determine the applicant's suitability for teaching as a career. When laying an educational foundation in early childhood, we need to understand that quality musical experiences from teachers are needed. It is also crucial for the government to provide an effective program to offer standard teaching instructions that correspond with the early childhood music curriculum. Promoting a working culture exhibited by countries with good early childhood education policies will help improve the quality of teacher education in Zambia. There is also a need to make sure early childhood music education receives enough financial support to help in providing relevant elementary music materials in schools. The government under the ministry of education should come up with evaluation methods on music teachers responsible for handling children's educations only teachers with high music skills, and reasonable evaluation of teaching methods that correspond with the child-centered music curriculum should be considered to handle music education in elementary stages of children's education.

\section{References}

[1] O. Shoaga, "Play and Learning: Inseparable Dimensions to Early Childhood Education," J. Educ. Soc. Res., vol. 2, no. 5, pp. 185-185, May 2015, doi: 10.5901/jesr.2015.v5n2p185.

[2] C. M. Thomas and M. A. M. Thomas, "Early Childhood Care and Education in Zambia: An Integral Part of Educational Provision?.," Curr. Issues Comp. Educ., vol. 11, pp. 6-14, 2009. Available at: Google Scholar. 
[3] B. Kalinde and D. Vermeulen, "Fostering children's music in the mother tongue in early childhood education: A case study in Zambia," South African J. Child. Educ., vol. 6, no. 1, p. 9, Dec. 2016, doi: 10.4102/sajce.v6i1.493.

[4] E. D. Otchere, "Sharing concerns: A direction for African music education," in Music Education in Africa, Abingdon, Oxon; New York, NY: Routledge, 2019. | Series: Routledge studies in music education: Routledge, 2019, pp. 59-75. doi: 10.4324/9780429201592-4

[5] B. Kalinde, "Cultural play songs in early childhood education in Zambia: In and outside of classroom practice." University of Pretoria, 2016. Available at: Google Scholar.

[6] A. K. Mumpuka, "The status of music education in the selected high schools in Lusaka Province, Zambia." North-West University, 2009. Available at: Google Scholar.

[7] M. Mwila, "Factors causing the non-teaching of music in Zambia: Case of Primary Schools in Chongwe District, Lusaka, Zambia.” University of Zambia, 2015. Available at: dspace.unza.zm.

[8] D. C. McCoy, S. S. Zuilkowski, H. Yoshikawa, and G. Fink, "Early Childhood Care and Education and School Readiness in Zambia," J. Res. Educ. Eff., vol. 10, no. 3, pp. 482-506, Jul. 2017, doi: 10.1080/19345747.2016.1250850.

[9] M. Oliver, M. Peggy, G. Colious, M. Situmbeko, and K. Christine, "Secondary School Teachers"e Preparedness in Implementing the Revised Education Curriculum Framework of 2013 in Zambia: A Pedagogical Perspective," Int. J. Res. Innov. Soc. Sci., vol. 5, no. 4, pp. 282-289, 2021. Available at: Google Scholar.

[10] R. Serpell and R. M. Mukela, "Systemic challenges for integration of ECDCE programmes with African cultures of early childhood socialization," in Pedagogies for Diverse Contexts, Routledge, 2018, pp. 141160. doi: $10.4324 / 9781351163927-14$

[11] S. Ministry of Education Vocational Training and Early Education, "Zambia education curriculum framework 2013." The Curriculum Development Centre Lusaka, 2013. Available at: unesco.org

[12] A. M. Banda, "Teacher Education and the Teaching of Subitizing in Early Childhood Centers in Lusaka Urban, Zambia," Texila Int. J. Acad. Res., vol. 5, no. 2, pp. 51-60, Oct. 2018, doi: 10.21522/TIJAR.2014.05.02.Art007.

[13] C. Philpott, "Musical learning," in Learning to Teach Music in the Secondary School, Routledge, 2005, pp. 31-46. doi: 10.4324/9780203977439-11

[14] C. Philpott and K. Evans, "Creativity and music education," in Learning to Teach Music in the Secondary School, 3rd edition. | London; New York: Routledge, 2016. |: Routledge, 2016, pp. 109-127. doi: 10.4324/9781315621203-9

[15] C. Philpott and C. Plummeridge, Issues in Music Teaching. Routledge, 2004. doi: $10.4324 / 9780203005699$

[16] B. Parsad and M. Spiegelman, "A Snapshot of Arts Education in Public Elementary and Secondary Schools: 2009-10. First Look. NCES 2011-078.,” National Center for Education Statistics. ERIC, 2011. Available at: Google Scholar.

[17] D. E. Southgate and V. J. Roscigno, "The Impact of Music on Childhood and Adolescent Achievement," Soc. Sci. Q., vol. 90, no. 1, pp. 4-21, Mar. 2009, doi: 10.1111/j.1540-6237.2009.00598.x.

[18] S.-E. Holgersen, "Music Education for Young Children in Scandinavia: Policy, Philosophy, or Wishful Thinking?," Arts Educ. Policy Rev., vol. 109, no. 3, pp. 47-54, Jan. 2008, doi: 10.3200/AEPR.109.3.4754.

[19] P. J. Krueger, "Beginning music teachers: Will they leave the profession?," Updat. Appl. Res. Music Educ., vol. 19, no. 1, pp. 22-26, Nov. 2000, doi: 10.1177/875512330001900105.

[20] A. M. Reynolds and S. L. Burton, "Serve and return: Communication foundations for early childhood music policy stakeholders," Arts Educ. Policy Rev., vol. 118, no. 3, pp. 140-153, Jul. 2017, doi: 10.1080/10632913.2016.1244779.

[21] Y. Lee et al., "Early childhood care and education: Worldwide challenges and progresses," Curr. Issues Comp. Educ., vol. 11, no. 1, pp. 3-5, 2009. Available at: Google Scholar. 
[22] G. Walubita, "Munsaka, E., \&amp; Kalinde, B. (2017) Laying the foundation for optimal outcomes in Early Childhood, University of Zambia Press, Lusaka, 172 pp. (A5), \$12.00 (paperback), ISBN 9789982-02-099-1," African J. Teach. Educ., vol. 8, pp. 254-260, Oct. 2019, doi: 10.21083/ajote.v8i0.5470.

[23] S. Lungu, B. Matafwali, and M. K. Banja, "Formative and summative assessment practices by teachers in early childhood education centres in Lusaka, Zambia," Eur. J. Educ. Stud., vol. 8, no. 2, pp. 45-64, 2021, doi: 10.46827/ejes.v8i2.3549.

[24] S. Lungu and B. Matafwali, "Play-Based Learning in Early Childhood Education (ECE) Centres In Zambia: A Teacher Perspective,” Eur. J. Educ. Stud., vol. 7, no. 12, pp. 356-369, 2020, doi: 10.46827/ejes.v7i12.3427.

[25] L. K. Scott, "Early Childhood Brain Development and Elementary Music Curricula: Are They in Tune?," Gen. Music Today, vol. 18, no. 1, pp. 20-27, Oct. 2004, doi: 10.1177/10483713040180010105.

[26] M. K. Mooto and Z. Lusaka, "Exploring The Provision of Early Childhood Education (ECE) In The Barotse Flood Plains, Mongu District, Western Province, Zambia,” 2015. Available at: Google Scholar.

[27] A. R. Addessi, F. Anelli, D. Benghi, and A. Friberg, "Child-Computer Interaction at the Beginner Stage of Music Learning: Effects of Reflexive Interaction on Children's Musical Improvisation," Front. Psychol., vol. 8, no. 65, pp. 1-21, Jan. 2017, doi: 10.3389/fpsyg.2017.00065.

[28] E. Fesseha and A. Pyle, "Conceptualising play-based learning from kindergarten teachers' perspectives," Int. J. Early Years Educ., vol. 24, no. 3, pp. 361-377, Jul. 2016, doi: 10.1080/09669760.2016.1174105.

[29] J. Bubikova-Moan, H. Næss Hjetland, and S. Wollscheid, "ECE teachers' views on play-based learning: a systematic review," Eur. Early Child. Educ. Res. J., vol. 27, no. 6, pp. 776-800, Nov. 2019, doi: 10.1080/1350293X.2019.1678717. 